\title{
Meningoencephalocele, bilateral anorchia with radial and fibular hemimelia in a piglet
}

\author{
ABIOLA, J. O. ${ }^{1}$, OMOTOSHO, O. O. ${ }^{1}$ and IGADO, O. O. ${ }^{2 *}$ \\ ${ }^{1}$ Department of Veterinary Medicine, University of Ibadan, Ibadan, Oyo, Nigeria \\ ${ }^{2}$ Comparative Anatomy, Neuroscience and Environmental Toxicology Unit, Department of Veterinary Anatomy, \\ University of Ibadan, 20001, Ibadan, Oyo, Nigeria \\ *E-mail: mayowaigado@yahoo.com
}

\begin{abstract}
Introduction: Birth defects still remain one of the major causes of economic wastage in livestock farming. It may be caused by a number of aetiologies. Meningoencephalocele results from neural tube defect during embryology. It is incompatible with life. Materials and methods: This is a case report of a stillbirth pig, which was presented with a swelling on the frontal part of the skull, and a number of other musculoskeletal defects. The affected piglet was farrowed with 5 other piglets by a 4 year old sow with previous uneventful farrowings. All other piglets in the litter showed no physical abnormalities post parturition. Results: Gross examination revealed meningocele with a circumference of $19 \mathrm{~cm}$. Necropsy and x-ray (dorso-ventral view) revealed skeletal deformities which involved the long bones and the axial skeleton. The long bones were considerably shortened, with some having a 'twisted' appearance, while the vertebral column showed scoliosis. X-ray also revealed non-closure of the frontal bone of the skull, which resulted in herniation of brain material. Other abnormalities included bilateral anorchia, anophthalmos, cleft lip, atresia ani and multiple skeletal deformities. A rudimentary phallus was present, but dissection of abdominal and pelvic cavities revealed absence of any identifiable reproductive organs (male or female). Conclusion: Abnormalities observed were not compatible with life. This is probably the first electronically documented report of meningoencephalocele of the pig, with the reported accompanying multi organ and skeletal abnormalities in Nigeria.
\end{abstract}

Keywords: meningoencephalocele, anorchia, hemimelia, anophthalmos, pig.

\section{Introduction}

Birth defects still remain one of the major causes of economic wastage in livestock farming. Visible defects at birth have been reported to occur in pigs at a prevalence estimated by different authors as $0.04 \%$ to $1.05 \%$. They are due to deviations from normal prenatal development which may be caused by several factors which could either be genetic or environmental (CUTLER, FAHY, CRONIN et al., 2006).

Meningoencephalocele, encephalocele, anencephaly, hydrocephalus and spinal bifida result from neural tube defects during embryonic development. These defects may be due to an unknown agent affecting the embryo at 12-16 days of development (CUTLER, FAHY, CRONIN et al., 2006). Meningoencephalocele is normally observed as a cyst-like swelling in the median part of the skull cap. It is a rare occurrence. The condition is classified as meningocoele when only the cerebrospinal fluid is found in the swelling, while it is classified as a meningoencephalocele when brain tissues are also present in the swelling (CHO, PARK, YOO et al., 2015).

Congenital skeletal deformities occur in pigs and are an important cause of lifelong deformity, disability and early degenerative disease. These conditions usually arise due to a deranged structure of the growth cartilage, the epiphysis, and/or the growth plate (CONNOLLY, JARAMILLO, HONG et al., 2004).

The present report is on the occurrence of meningoencephalocele, anophthalmos, bilateral anorchia with radial and fibular hemimelia in a piglet.

\subsection{Case history, necropsy and radiological findings}

A stillborn piglet was recovered from the Swine Production Unit of the Teaching and Research Farm, University of Ibadan, Nigeria. It was farrowed along with 5 other piglets after a full term gestation by a 4 year old sow with a record of four previous uneventful farrowings.

Gross external examination suggested the piglet to be male, with a crown rump length of $24.5 \mathrm{~cm}$, and a height (from crown to base) of $10 \mathrm{~cm}$. A sac-like, soft protrusion (cele) of $19 \mathrm{~cm}$ in circumference was observed on the region of the frontal bone, along the midline on top of the piglet's head (Figure 1). The skull appeared to be dorsoventrally compressed, with a right lateral deviation of the skull. Both nares were malformed, and both presented a longitudinal slit on the lateral sides. No eyes or eyelids were observed, although the orbit was palpable. A small fold was present where the left eyeball should have been. Cleft lip was observed, but no cleft palate. There was a bilateral duplication of both pinnae, with the left duplicate being larger (Figure 1). Digital palpation suggested the presence of brain material in the cele. Aspiration of the cele revealed a serosanguinous fluid, with a volume of about $100 \mathrm{ml}$ when lanced. Further digital palpation of the frontal bone revealed non-closure of the frontal suture. Dissection of the cele revealed the presence of brain matter, giving the diagnosis of meningoencephalocele (or cranium bifidum) (Figure 2).

There was atresia ani, no scrotal sac was observable, and testicles were non-palpable. Prior to dissection, piglet was 


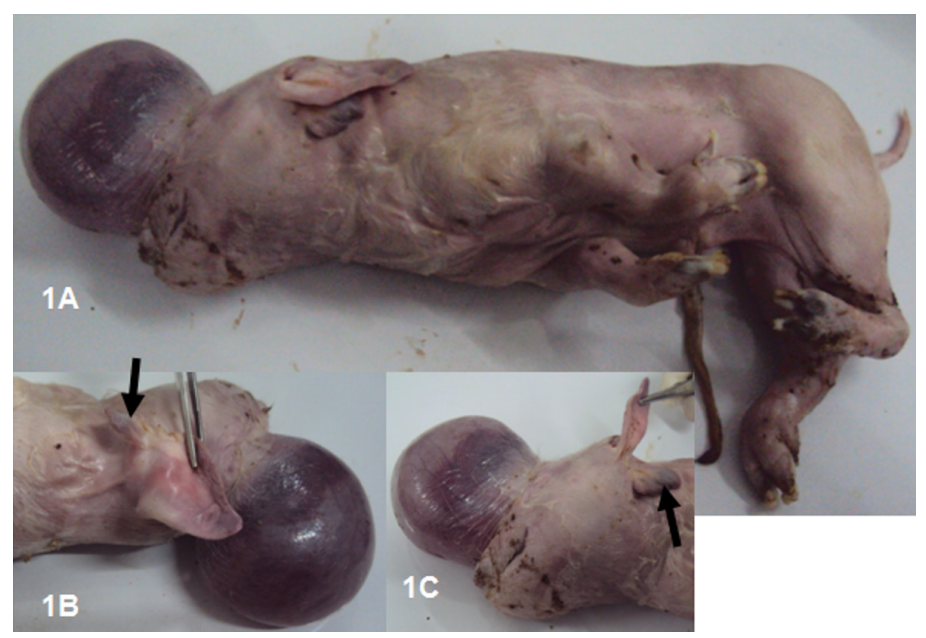

Figure 1. Piglet with meningoencephalocele. Note the twisted and deviated appearance of the two forelimbs and the asymmetry observed in the hindlimbs (1A), the duplication of the left and right pinnae (arrows in $1 \mathrm{~B}$ and $1 \mathrm{C}$ respectively). Note also the absence of palpebral fissure on both sides (1A, $1 \mathrm{~B}$ and $1 \mathrm{C})$.

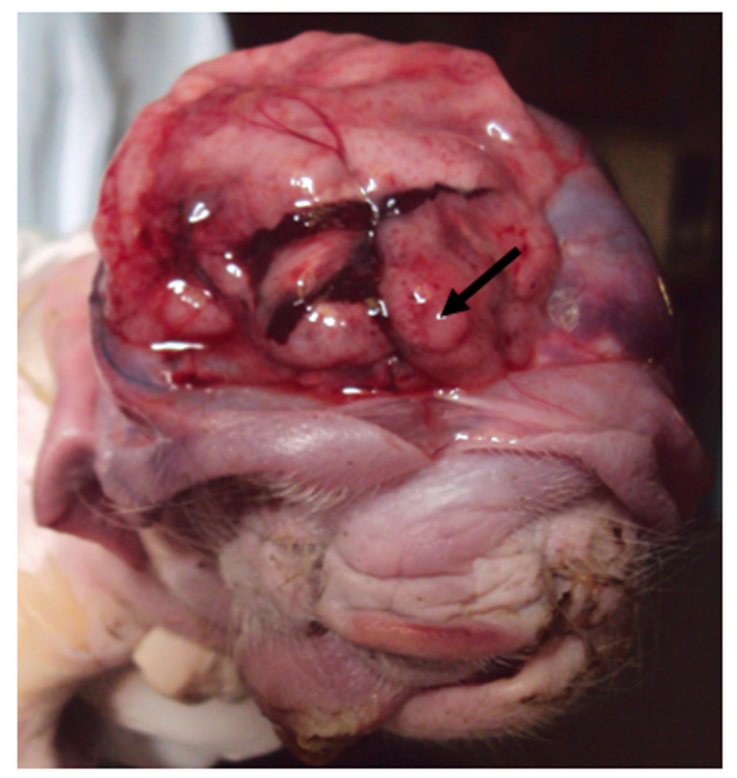

Figure 2. The dorsal aspect of the skull of the piglet, the flap of skin covering the meningoencephalocele has been reflected. Arrow indicates protruding brain tissue.

assumed to be a male due to the absence of vulva, and the presence of a rudimentary phallus.

Upon gross musculoskeletal examination, the joints of the forelimbs appeared enlarged, with a caudo-lateral deflection of the humerus causing the humero-ulna joint to deviate laterally. Metacarpals appeared absent, and the digits of all limbs were splayed. There was asymmetry of the two hindlimbs, with a medial deviation of the femur and the tibio-fibula bones of both hindlimbs. Also, a shortening of the left metatarsal, with an absence of the dewclaw on the same limb was observed (Figure 1A). Observed also was a reduction in muscle mass of all the limbs. There was right lateral deviation of the vertebral column, which was more pronounced when the animal was placed on sternal recumbency.
Necropsy revealed macroglossia. The shape of the heart appeared normal, but heart muscles were flabby. Both kidneys were atretic, the left kidney measured $21.87 \mathrm{~mm}$ from the cranial to the caudal pole, while the right measured $20.92 \mathrm{~mm}$. No adrenals were observable. The gastrointestinal tract appeared normal, but the testes and epididymis were completely absent (anorchia) and no other reproductive organs were visible grossly. The bladder was present, but flaccid and devoid of urine contents.

A plain radiograph was done, dorso-ventral view. Radiological findings revealed a crania bifida of the skull in the fontanelle region of the frontal bone, appearing as a widening of the frontal suture. Also, a curvature of the vertebral column was observed. The humerus had a shortened and stunted appearance, while all the bones distal to the humerus showed dysgenesis. The skeletal abnormality in the forelimbs appeared symmetrical. The long bones of the hindlimbs also displayed a considerable shortening and dysgenesis (hemimelia) (Figures 1 and 3).

\section{Discussion}

Brain hernia is a skull defect which is due to a cleft in the skull, through which meninges may protrude (meningocele) or meninges and brain tissue (encephalocele). It reflects an imperfect or incomplete osteogenesis of the skull (CHO, PARK, YOO et al., 2015).

Encephalocele is a neural tube defect that manifests at different locations of the skull. Its aetiology is unclear, but previous pathological examinations in humans have shown that a portion of the brain or meninges herniates through the skull, indicating a failure of fusion of the mesodermal tissue that overlies the neural tube in embryologic development (LEMIRE, LOESER, LEECH et al., 1975; FISHER and SMITH, 1981). The cleft (or non fusion) that we observed in the skull in this study was seen on the frontal bone. Different teratogens have been implicated in the aetiogenesis of encephalocele, one of which is gestational hyperthermia (FISHER and SMITH, 1981). Although this current case was reported in the tropics, there was no record of very high 


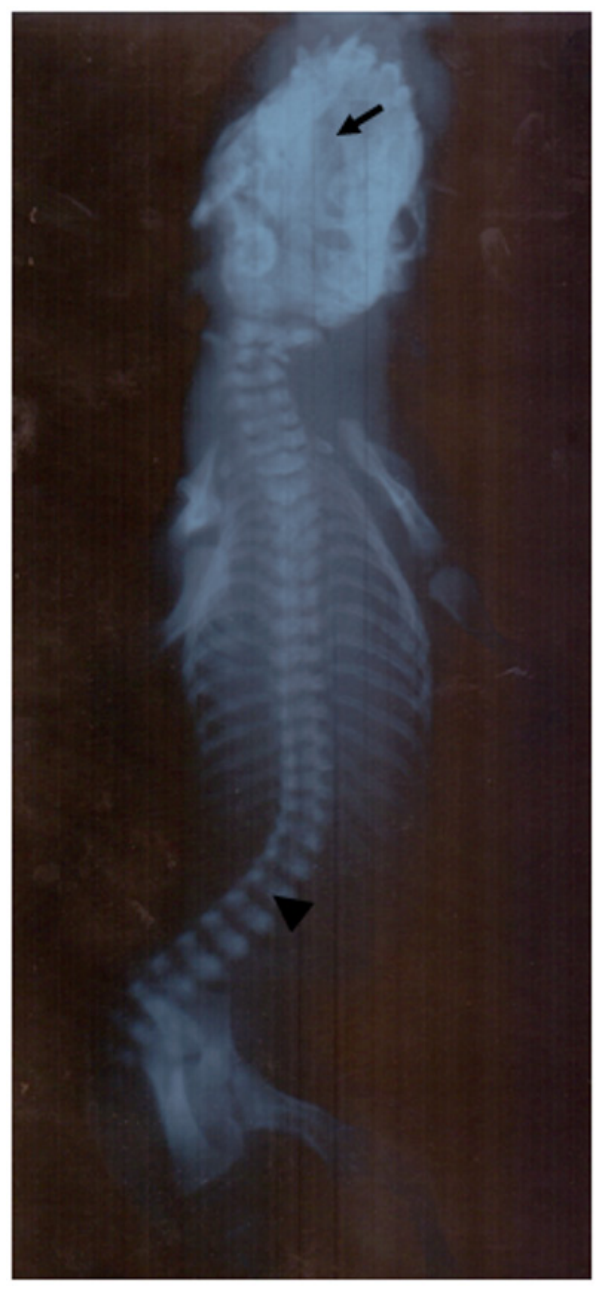

Figure 3. X-ray of the dorso-ventral view. Note the curvature of the vertebral column (arrow head) and the cranium bifidum (black arrow).

or extreme ambient temperature during the gestation period, and the pen of the dam was well aerated.

In the form of meningocele, this condition has been reported in ruminants, horses, pigs, dogs and cats (RAOOFI, DEHGHAN, MARDJANMEHR et al., 2004), but when accompanied with multiple congenital anomalies has been reported in the cattle (LAPOINTE, LACHANCE and STEFFEN, 2000). Generally, in humans, a few syndromes have been associated with meningoencephalocele, namely Knobloch syndrome (associated also with sight defects) and Walker-Warburg syndrome (involving eye defects and muscular dystrophy) (RAMAMURTHI, SRIDHAR and VASUDEVAN, 2005). This case however could not be said to be either of these two syndromes, due to the more varied systems affected.

Bilobed ears which was observed in this case has been previously reported to be caused by a lethal factor, supposed to be recessive and the abnormality is sometimes accompanied by cleft palate and hind leg malformations (OLLIVIER and SELLIER, 1982). Reduction in size of the ears, also observed in this piglet, has been shown to occur either alone or in connection with skull defects. This condition is considered to be hereditary, but has also been attributed to external factors (OLLIVIER and SELLIER, 1982). Accessory ears, cleft lip (as seen in this report), cleft palate and arrested ascension of the kidneys have been linked to maternal vitamin A deficiency (HALE, 1935; MADEN, 2001). Examination of the feed at the time of report did not show vitamin A deficiency or deficiency of any other vitamin. It should be noted however that this deficiency could have occurred earlier, at an essential time in the embryologic development, and could not be verified at the time of report.

Genetic and non-genetic causes have been implied in eye defects, especially lack of vitamin A (OLLIVIER and SELLIER, 1982; MADEN, 2001; HORNBY, WARD and GILBERT, 2003). Vitamin A deficiency in dams has been implicated in many 'eye weaknesses' suffered by animals, humans included. From as far back as 1935, Hale reported the implication of vitamin A deficiency in anophthalmos in pigs. Congenital blindness occurs frequently in pigs and generally manifests as various degrees of microphthalmia. Several reports however have shown that a genetic basis exists for blindness in pigs (OLLIVIER and SELLIER, 1982).

Multiple skeletal abnormalities occur in pigs, although, in many cases the genetic study of skeletal anomalies is made difficult because some of them arise as a result of metabolic disturbances of non-genetic origin occurring during embryonic development (OLLIVIER and SELLIER, 1982). In this case, the other abnormalities observed made it impossible for the piglet to survive. The multiple skeletal deformities alone could have resulted into the piglet being culled since standing up and moving around would have been practically impossible.

Atresia ani (closure of the anal outlet) occurs more frequently in the pig than any other species and is possibly the most important cause of intestinal obstruction (ANDERSON and ST-JEAN, 2012). It occurs with an incidence of $0.1-1 \%$, is transmitted genetically, but may occur spontaneously (WIEDEMANN, FRIES and THALLER, 2005).

The sex of a mammalian embryo is genetically determined at the time of fertilization, while the genital ridges remain morphologically indifferent during the first weeks of gestation. The Sry gene has been reported to be responsible for the differentiation of the testis, and proliferation of the primitive sex cords (HYTTEL, SINOWATZ and VEJLSTED, 2010). This piglet had no reproductive organs, which could imply that some of the anomalies observed were genetic or could probably have occurred at the time of fertilization. The other structures affected (urinary and musculoskeletal system) were structures which develop later in embryological life.

The sow in this case report was raised intensively, in a semi-open pen, and not allowed to roam freely, so the possibility of ingesting a toxin was relatively low. Moreover, there was no other dam on the farm, at the time of reporting, with the incidence of any congenital anomaly. Although it should be noted that we could not obtain information on the complete farrowing and mating history of the sow's parents.

As chromosomal damage and defects could not be ascertained in the sire and dam, the owner was advised to separate them, and avoid using them for further breeding. Also, we advised the owner to review the quality of the feed, pre- and post mating, to rule out vitamin deficiency (especially vitamin A) in spite of the fact that only one piglet out of six showed abnormalities.

\section{Conflict of interest}

The authors declare that they have no conflict of interest. 


\section{References}

ANDERSON, DE. and ST-JEAN, G. Anaesthesia and Surgical Procedures in Swine. In: ZIMMERMAN, JJ., KARRIKER, LA., RAMIREZ, A., SCHWARTZ, KJ. and STEVENSON, GW. (Eds.). Diseases of Swine. 10th ed. John Wiley \& Sons Inc, 2012. p. 119-138.

CHO, IC., PARK, YS., YOO, JG., HAN, SH., CHO, SR., PARK, HB., JEON, KL., MOON, KA., CHO, HS. and KANG, TY. Two cases of meningocele and meningoencephalocele in Jeju native pigs. BMC Veterinary Research, 2015, vol. 11, n. 1, p. PMC4399108. PMid:25889174. http://dx.doi.org/10.1186/s12917-015-0404-y.

CONNOLLY, SA., JARAMILLO, D., HONG, JK. and SHAPIRO, F. Skeletal development in fetal pig specimens: $\mathrm{mr}$ imaging of femur with histologic comparison. Radiology, 2004, vol. 233, n. 2, p. 505-514. PMid:15375230. http://dx.doi.org/10.1148/radiol.2332030131.

CUTLER, RS., FAHY, VA., CRONIN, GM. and SPICER, EM. Preweaning Mortality. In STRAW, BE., ZIMMERMAN, JJ., D' ALLIARE, S. and TAYLOR, DJ. (Eds.). Diseases of Swine. 9th ed. Iowa: Blackwell Publishing, 2006. p. 1005-1006.

FISHER, NL. and SMITH, DW. Occipital encephalocele and early gestational hyperthermia. Pediatrics, 1981, vol. 68, n. 4, p. 480-483. PMid:7322680.

HALE, F. The relation of vitamin A to anophthalmos in pigs. American Journal of Ophthalmology, 1935, vol. 18, n. 12, p. 1087-1093. http:// dx.doi.org/10.1016/S0002-9394(35)90563-3.

HORNBY, SJ., WARD, SJ. and GILBERT, CE. Eye birth defects in humans may be caused by a recessively-inherited genetic predisposition to the effects of maternal vitamin A deficiency during pregnancy. Medical Science Monitor, 2003, vol. 9, n. 11, p. HY23-HY26. PMid:14586282.

HYTTEL, P., SINOWATZ, F. and VEJLSTED, M. Essentials of domestic animal embryology. Philadelphia: Saunders Elsevier, 2010. p. 262-264.
LAPOINTE, JM., LACHANCE, S. and STEFFEN, DJ. Tibial Hemimelia, Meningocele, and Abdominal Hernia in Shorthorn Cattle. Veterinary Pathology, 2000, vol. 37, n. 5, p. 508-511. PMid:11055885. http://dx.doi.org/10.1354/vp.37-5-508.

LEMIRE, RJ., LOESER, JD. and LEECH, RW. and ALVORD, EC. Normal and abnormal development of the human nervous system. New York: Harper and Row Publishers Inc, 1975.

MADEN, M. Vitamin A and the developing embryo. Postgraduate Medical Journal, 2001, vol. 77, n. 910, p. 489-491. PMid:11470926. http://dx.doi.org/10.1136/pmj.77.910.489.

OLLIVIER, L. and SELLIER, P. Pig genetics: a review. Annales de Genetique et de Selection Animale, 1982, vol. 14, n. 4, p. 481-544. PMid:22896254. http://dx.doi.org/10.1186/1297-9686-14-4-481.

RAMAMURTHI, R., SRIDHAR, K. and VASUDEVAN, MC. Textbook of operative neurosurgery. New Delhi: B.I. Publications Pvt Ltd, 2005. 283 p. vol. 1.

RAOOFI, A., DEHGHAN, MM., MARDJANMEHR, SH., SOROORI, S., HEMMATZADEH, F., LOTFOLLAHZADEH, S. and NEKOEI, SH. Cranium bifidum with meningocele in a lamb. Small Ruminant Research, 2004, vol. 55, n. 1-3, p. 253-256. http:// dx.doi.org/10.1016/j.smallrumres.2004.02.006.

WIEDEMANN, S., FRIES, R. and THALLER, G. Genome wide scan for anal atresia in swine identifies linkage and association with a chromosome region on Sus scrofa chromosome 1. Genetics, 2005, vol. 171, n. 3, p. 1207-1217. PMid:16020797. http://dx.doi. org/10.1534/genetics.104.032805.

Received November 16, 2016 Accepted August 7, 2017 